15 Thun MJ, Day Lally CA, Calle EE, Flanders WD, Heath CW Jr. Excess mortality among cigarette smokers: changes in a 20-year interval [with comments]. Am J Public Health 1995;85:1223-30.

16 Baron JA, Vecchia CL, Levi F. The antiestrogenic effect of cigarette smoke in women. Am J Obstet Gynecol 1990;162:502-14.

17 Michnovicz IJ, Hershcopf RJ, Naganuma H, Bradlow HL, Fishman J. Increased 2-hydroxylation of estradiol as a possible mechanism for the anti-estrogenic effect of cigarette smoking. $N$ Engl $J$ Med anti-estrogenic

1986;315:1305-9.
18 Michnovicz JJ, Hershcopf RJ, Haley NJ, Bradlow HL, Fishman J. Cigarette smoking alters hepatic estrogen metabolism in men: implication for atherosclerosis. Metabolism 1989;38:537-41.

19 Grodstein F, Stampfer M. The epidemiology of coronary heart disease and estrogen replacement in postmenopausal women. Prog Cardiovasc Dis $1995 \cdot 38: 199-210$

20 Stampfer MJ, Colditz GA, Willett WC, Manson JE, Rosner B, Speizer FE, et al. Postmenopausal estrogen therapy and cardiovascular disease. Tenyear follow-up from the nurses' health study [with comments]. $N$ Engl Med 1991;325:756-62.
21 Miller VT, Muesing RA, LaRosa JC. Effects of conjugated equine estrogen with and without three different progestogens on lipoproteins, high-density lipoprotein subfractions, and apolipoprotein A-4. Obstet Gynecol 1991;77:235-40.

22 Writing Group for the PEPI Trial. Effects of estrogen or estrogen/ progestin regimens on heart disease risk factors in postmenopausal women. JAMA 1995;273:199-208

23 Williams JK, Adams MR, Klopfenstein HS. Estrogen modulates response of atherosclerotic coronary arteries. Circulation 1990;81:1680-7.

24 Criqui MH, Suarez L, Barrett Connor E, McPhillips J, Wingard DI, Garland C. Postmenopausal estrogen use and mortality. Results from a prospective study in a defined, homogeneous community. Am J Epidemiol 1988;128:606-14.

25 Lindenstrøm E, Boysen G, Nyboe J. Lifestyle factors and risk of cerebrovascular disease in women. Stroke 1993:24:1468-72.

(Accepted 5 December 1997)

\title{
Ecological study of reasons for sharp decline in mortality from ischaemic heart disease in Poland since 1991
}

\author{
Witold A Zatonski, Anthony J McMichael, John W Powles
}

\begin{abstract}
Objective: To investigate the reasons for the decline in deaths attributed to ischaemic heart disease in Poland since 1991 after two decades of rising rates. Design: Recent changes in mortality were measured as percentage deviations in 1994 from rates predicted by extrapolation of sex and age specific death rates for 1980-91 for diseases of the circulatory system and selected other categories. Available data on national and household food availability, alcohol consumption, cigarette smoking, socioeconomic indices, and medical services over time were reviewed.

Main outcome measures: Age specific and age standardised rates of death attributed to ischaemic heart disease and related causes.

Results: The change in trend in mortality attributed to diseases of the circulatory system was similar in men and women and most marked $(>20 \%)$ in early middle age. For ages 45 to 64 the decrease was greatest for deaths attributed to ischaemic heart disease and atherosclerosis (around 25\%) and less for stroke $(<10 \%)$. For most of the potentially explanatory variables considered, there were no corresponding changes in trend. However, between 1986-90 and 1994 there was a marked switch from animal fats (estimated availability down 23\%) to vegetable fats (up 48\%) and increased imports of fruit. Conclusion: Reporting biases are unlikely to have exaggerated the true fall in ischaemic heart disease; neither is it likely to be mainly due to changes in smoking, drinking, stress, or medical care. Changes in type of dietary fat and increased supplies of fresh fruit and vegetables seem to be the best candidates.
\end{abstract}

\section{Introduction}

From 1960 to 1991 mortality from diseases of the circulatory system in Poland was high and increasing. Death certification rates for this group of causes rose by about $70 \%$ in men and $15 \%$ in women, and in both sexes mortality from ischaemic heart disease roughly doubled. ${ }^{1-4}$ Since 1991, however, the fall in death certification rates for ischaemic heart disease seems to have been larger than that previously observed in any country in peacetime. This sharp change in trend suggests a curtailment of the final, fatal steps of the disease in people with advanced coronary atherosclerosis.

The unplanned natural experiments taking place in Poland and neighbouring countries in association with the unusually rapid political and economic transformations that began in the late 1980s may elucidate why mortality from ischaemic heart disease varies more between populations and over time than has previously been accounted for by the classic risk factors. ${ }^{5}$ Analyses in populations may yield such leads, notwithstanding the difficulties they face in taking adequate account of concurrent changes in confounders. ${ }^{6}$ Such analyses may point to widely shared influences on disease incidence, especially those acting late in the disease process. ${ }^{\text {? }}$

We considered the possible roles of concomitant changes in the availability of foods and alcohol, smoking prevalence, socioeconomic indices, and medical care in explaining the recent decline in mortality from ischaemic heart disease in Poland.

\section{Subjects and methods}

Mortality data are from the Polish system of vital statistics and the mortality data bank of the World Health Organisation in Geneva. There were no significant inconsistencies between the two data sets.

National death certification rates were examined for five year age groups between 35 and $\geqslant 85$ for 1970 94. Rates for ages 45-64 were standardised by five year age groups using weights of $6,5,4$, and 4 respectively. ${ }^{8}$ To minimise the effects of short term perturbations in rates around 1989-91, the subsequent changes in rates were measured as the percentage deviations in the reported rates for 1994 from rates predicted for 1994 by extrapolating the linear trends for 1980-91 (after
Department of Epidemiology and Cancer Prevention, Maria

Sklodowska-Curie Memorial Cancer Centre and Institute of Oncology, 02-781 Warsaw, Poland

Witold A Zatonski, professor

Department of Epidemiology and Population

Sciences, London School of Hygiene and Tropical

Medicine, London

WC1E 7HT

Anthony J

McMichael,

professor

Institute of Public Health, Cambridge CB2 2SR

John W Powles,

lecturer

Correspondence to: Professor Zatonski zatonskiw@ coi.waw.pl

BMJ 1998;316:1047-51 
Table 1 Death certification rates for circulatory disease, cancer, injury, and all causes in Poland 1970-94. Values are age standardised rates per 100000 population for ages $45-64^{*}$

\begin{tabular}{llllllllllllll} 
ICD- 8, ICD-9 & 1970 & 1975 & 1980 & 1985 & 1986 & 1987 & 1988 & 1989 & 1990 & 1991 & 1992 & 1993 & 1994 \\
\hline
\end{tabular}

\begin{tabular}{|c|c|c|c|c|c|c|c|c|c|c|c|c|c|c|}
\hline \multirow{2}{*}{\multicolumn{15}{|c|}{ Men }} \\
\hline & & & & & & & & & & & & & & \\
\hline All diseases of circulatory system & $390-459$ & 486 & 539 & 658 & 704 & 722 & 729 & 712 & 732 & 742 & 777 & 738 & 690 & 650 \\
\hline $\begin{array}{l}\text { Heart disease (excluding rheumatic disease) and } \\
\text { hypertension }\end{array}$ & $400-405,410-429$ & 327 & 368 & 454 & 478 & 496 & 498 & 481 & 499 & 501 & 529 & 498 & 463 & 438 \\
\hline Hypertensive disease & $400-405$ & 29 & 27 & 29 & 38 & 35 & 35 & 34 & 33 & 33 & 39 & 36 & 34 & 32 \\
\hline Atherosclerosis and diseases of arteries & $440-448$ & 83 & 82 & 97 & 113 & 114 & 120 & 120 & 123 & 126 & 132 & 122 & 111 & 102 \\
\hline Stroke & $430-438$ & 51 & 65 & 85 & 87 & 90 & 91 & 90 & 91 & 94 & 98 & 100 & 99 & 94 \\
\hline All cancer (except lung) & $140-161,163-208$ & 238 & 242 & 255 & 277 & 280 & 286 & 290 & 290 & 287 & 287 & 287 & 285 & 284 \\
\hline Lung cancer & 162 & 92 & 115 & 147 & 184 & 183 & 188 & 194 & 196 & 196 & 202 & 187 & 190 & 190 \\
\hline Injury & E800-E999 & 128 & 146 & 169 & 162 & 160 & 157 & 150 & 160 & 183 & 197 & 189 & 172 & 177 \\
\hline All causes & $1-999$ & 1326 & 1364 & 1580 & 1670 & 1677 & 1684 & 1659 & 1702 & 1735 & 1824 & 1748 & 1659 & 1618 \\
\hline \multicolumn{15}{|l|}{ Women } \\
\hline All diseases of circulatory system & $390-459$ & 230 & 225 & 249 & 265 & 262 & 266 & 257 & 261 & 257 & 257 & 248 & 229 & 223 \\
\hline $\begin{array}{l}\text { Heart disease (excluding rheumatic disease) and } \\
\text { hypertension }\end{array}$ & $400-405,410-429$ & 128 & 118 & 131 & 145 & 145 & 147 & 139 & 147 & 144 & 146 & 142 & 131 & 128 \\
\hline Hypertensive disease & $400-405$ & 28 & 23 & 22 & 28 & 27 & 27 & 24 & 24 & 24 & 24 & 22 & 19 & 21 \\
\hline Atherosclerosis and diseases of arteries & $440-448$ & 35 & 35 & 38 & 42 & 41 & 44 & 45 & 44 & 44 & 43 & 39 & 35 & 32 \\
\hline Stroke & $430-438$ & 39 & 47 & 53 & 53 & 53 & 54 & 53 & 53 & 51 & 50 & 50 & 47 & 50 \\
\hline Other circulatory diseases & 390-398, 441-459 & 28 & 25 & 26 & 24 & 23 & 21 & 20 & 17 & 18 & 17 & 16 & 15 & 14 \\
\hline All cancer (except lung) & $140-161,163-208$ & 221 & 221 & 225 & 224 & 223 & 224 & 225 & 222 & 218 & 221 & 220 & 216 & 216 \\
\hline Lung cancer & 162 & 11 & 14 & 19 & 20 & 22 & 22 & 24 & 24 & 25 & 27 & 26 & 27 & 27 \\
\hline Injury & E800-E999 & 32 & 32 & 32 & 32 & 33 & 33 & 29 & 32 & 34 & 36 & 33 & 33 & 31 \\
\hline All causes & $1-999$ & 668 & 644 & 674 & 685 & 678 & 678 & 664 & 669 & 662 & 672 & 655 & 621 & 615 \\
\hline
\end{tabular}

* Directly age standardised, by 5 year age groups, to the world standard population (weights 6,5 , 4, and 4).

confirming the goodness of a linear fit). Categories of primary interest were all diseases of the circulatory system (codes 390-459 of the ninth revision of the international classification of diseases (ICD-9)), all non-rheumatic heart disease plus hypertension (400405, 410-429), ischaemic heart disease (410-414), hypertensive disease (400-405), atherosclerosis and diseases of the arteries (440-448), cerebrovascular disease (430-438), and other circulatory diseases (390$398,441-459)$. Deaths from influenza and pneumonia (480-487) were checked to see whether they contributed to short term fluctuations.

Available data from national food balance sheets and national household budget surveys were reviewed for salient changes since 1989. Polish food balance sheets have been prepared according to the protocols of the Food and Agriculture Organisation for each of the years under consideration and provide estimates of quantities of foods potentially available for human consumption. ${ }^{9}$ Published estimates of the availability of fats, by animal or vegetable source and by saturation class, were used. These estimates were derived using national food composition tables to estimate the average composition of the aggregate categories of foods in the food balance sheets-and then using constant conversion factors throughout the whole period under consideration. ${ }^{7}$ Changes inferred from food balance sheets were cross checked with data from the ongoing, standardised, household budget survey.

Data on smoking prevalence were obtained from national smoking surveys, based on probability samples and conducted using unchanging methods by the Department of Epidemiology and Cancer Prevention of the National Cancer Institute, Warsaw. ${ }^{10}$ Estimates of alcohol consumption, from the Polish national statistical office, have tried to include the contributions of smuggling and home distilling.

\section{Results}

Mortality trends by sex and age group for the categories of circulatory system disease considered were mostly roughly linear during 1980-91. For all diseases of the circulatory system the percentage falls to 1994 relative to the rates predicted by extrapolating the linear trends from 1980 to 1991 were similar in men and women, greatest at ages 35-60 (when they exceeded 20\% in several age-sex categories), and more modest above age 70 (mostly below 10\%). (For the five year age groups between 40 and 69 all but one of the sex specific slopes were significantly different from zero.) The change in trend occurred consistently after 1991.

Table 1 shows age standardised death rates for selected causes for people aged 45-64. In this age group the percentage falls in 1994 were $19 \%$ for men and $17 \%$ for women for all diseases of the circulatory system, $26 \%$ for men and $25 \%$ for women for ischaemic heart disease, and 8\% for men and 4\% for women for stroke. (The slope coefficients were significant $(\mathrm{P}<0.05)$, except for mortality from stroke in women.)

Deaths coded as influenza and pneumonia were relatively constant during the study period (data not shown). Death certification rates for lung cancer plateaued for middle aged men in the late 1980s and for women in the early 1990s (table 2).

Table 2 and the figure show data on diet, smoking, and alcohol consumption. The most striking change was the switch from animal to vegetable fats. The estimated ratio of polyunsaturated to saturated fat, below 0.35 during the 1980 s, was 0.49 by 1994 . Estimated 
Table 2 Estimates of availability of selected foods, amount of fat from animal and vegetable sources, ratio of polyunsaturated to saturated fat, availability of alcohol, and prevalence of smoking in Poland, 1970-94

\begin{tabular}{|c|c|c|c|c|c|c|c|c|c|c|c|c|c|}
\hline Amount per person year & 1970 & 1975 & 1980 & 1985 & 1986 & 1987 & 1988 & 1989 & 1990 & 1991 & 1992 & 1993 & 1994 \\
\hline Meat $(\mathrm{kg})^{7}$ & 53.0 & 70.3 & 74.0 & 60.2 & 66.0 & 66.7 & 68.3 & 68.6 & 68.6 & 73.2 & 70.3 & 67.5 & 62.5 \\
\hline Fruits $(\mathrm{kg})^{7}$ & 32.8 & 34.4 & 37.7 & 28.9 & 35.7 & 18.9 & 32.2 & 31.2 & 28.9 & 37.2 & 40.7 & 45.2 & 34.6 \\
\hline Vegetables (excluding potatoes) $(\mathrm{kg})^{7}$ & 111 & 109 & 101 & 105 & 114 & 116 & 115 & 116 & 119 & 126 & 116 & 122 & 116 \\
\hline Milk (litres) ${ }^{7}$ & 262 & 264 & 262 & 273 & 280 & 270 & 271 & 260 & 241 & 231 & 217 & 209 & 200 \\
\hline Eggs $(\mathrm{No})^{7}$ & 186 & 209 & 223 & 220 & 209 & 199 & 203 & 194 & 190 & 175 & 173 & 157 & 146 \\
\hline Alcohol (litres of ethanol) ${ }^{1011}$ & 5.2 & 6.9 & 8.4 & 6.8 & 6.9 & 7.0 & 6.8 & $7.5^{*}$ & ND & $9.6^{*}$ & $10.2^{*}$ & ND & $9.0^{*} \dagger$ \\
\hline Fats from animal sources $(\mathrm{kg})^{7}$ & 87.5 & 99.6 & 104.9 & 96.0 & 102.0 & 101.4 & 101.2 & 101.4 & 97.1 & 95.8 & 91.4 & 86.1 & 77.2 \\
\hline Fats from vegetable sources $(\mathrm{kg})^{7}$ & 23.8 & 25.3 & 26.4 & 26.0 & 25.7 & 27.1 & 28.4 & 28.2 & 25.1 & 27.2 & 32.1 & 35.7 & 39.8 \\
\hline Ratio of polyunsaturated to saturated fat ${ }^{7}$ & 0.34 & 0.33 & 0.32 & 0.33 & 0.32 & 0.33 & 0.34 & 0.34 & 0.33 & 0.36 & 0.41 & 0.46 & 0.49 \\
\hline \multicolumn{14}{|c|}{ Prevalence of smoking $(\%$ of people aged $\geqslant 16) \ddagger$} \\
\hline Men & ND & 59.3 & $62.2 \S$ & 54.8 & 54 & 53.1 & 51.6 & ND & 51.5 & 47.8 & 52.5 & 47.9 & 50.4 \\
\hline Women & ND & 17.8 & $30.3 \S$ & 27.9 & 27.1 & 22 & 25.2 & ND & 24.6 & 24.7 & 22.6 & 25.4 & 23.3 \\
\hline
\end{tabular}

$\mathrm{ND}=$ no data. ${ }^{*}$ Estimates are more uncertain (smuggling is included). $† 1995$. ¥Surveys of Department of Epidemiology and Cancer Prevention, National Cancer Institute, Warsaw. §1982.

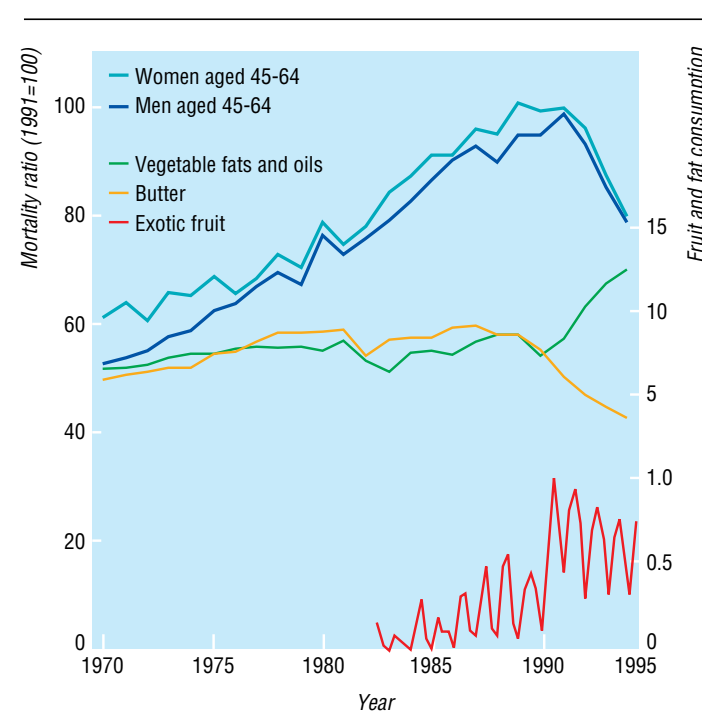

Mortality ratios for ischaemic heart disease plus atherosclerosis and arterial diseases, with estimates of butter and vegetable fats and oils $\left(\mathrm{kg} /\right.$ person/year) ${ }^{7}$ and of exotic fruits $(\mathrm{kg} / \text { person/quarter })^{12}$ available for consumption by quarter from 1970 to 1994. Data for years are plotted to mid-year and for quarters to mid-quarter. Mortality ratios are age standardised

household availability of exotic fruit-for example, imported citrus fruits and bananas-doubled from 1991. Trends evident in the household budget surveys accorded with those shown by the food balance sheets.

Alcohol consumption rose sharply (perhaps by $30-40 \%)$ immediately after the political changes and subsequently declined.

\section{Discussion}

Polish mortality statistics cover all Polish nationals irrespective of where they die. ${ }^{13}$ The recording of deaths occurring within Poland has remained almost complete during the transition period. ${ }^{11}$ Any bias from underreporting of deaths of people temporarily abroad would have been maximal during 1989-91 and could not account for progressive falls after 1991. There is no evidence that the denominator was progressively inflated after $1991 .^{14}$
Changes in certifying and coding practices could not explain the fall in mortality from diseases of the circulatory system because there is no other major category to which so many deaths could have been transferred (and neither is there suggestive evidence). Polish certification and coding practices have differed from those in the West. ${ }^{15}$ A larger proportion of deaths has been attributed to hypertensive disease in Poland than elsewhere-in many cases because it is recorded as the underlying cause when elsewhere this would be recorded as stroke. Similarly, a larger proportion of deaths has been attributed to atherosclerosis and arterial diseases-in many cases where the death would elsewhere be attributed to ischaemic heart disease. (This pattern of attribution has also been shown for the former German Democratic Republic. ${ }^{16}$ ) Death certification rates for both hypertensive disease and stroke have shown modest changes in parallel since 1991, while rates for atherosclerosis and arterial disease have fallen in parallel with those for ischaemic heart disease. The relative changes in attributed cause cannot be due to a convergence towards Western practice because such a convergence would have increased the proportion of circulatory deaths assigned to ischaemic heart disease. The decline in mortality from ischaemic heart disease is therefore unlikely to have been exaggerated by information error.

\section{Magnitude of change}

For men aged 45-64 the proportional reduction in 1994 was $26 \%$ when calculated as a departure from the trend during 1980-91, 20\% when compared with the peak year of 1991, and 16\% when 1994 was compared (more conservatively) with the three years before that peak year. For women the corresponding figures were $25 \%, 16 \%$, and $16 \%$.

This decline is apparently without precedent in peacetime. During the second world war mortality from circulatory diseases in German occupied Norway fell by around $20 \%$ within 2-3 years..$^{17}$ This accompanied dramatic enforced dietary changes-notably, a radical decrease in the consumption of meat, whole milk, cream, cheese, eggs, and margarine and a considerable increase in the consumption of fish and fresh vegetables. ${ }^{18}$ During the late 1960 s and 1970 s the trend in male mortality from ischaemic heart disease changed sharply in several Western countries, including Australia, New Zealand, the United States, Finland, 
and Belgium. In Australia-where the change in trend was perhaps the sharpest-male mortality at ages 45 to 64 fell about 12\% below its previous trend in the third year after it peaked, ${ }^{19}$ which is well below the corresponding figure in Poland.

\section{Possible causes}

Neither access to medical services nor their effectiveness has obviously improved since 1989 . The health service budget did not increase after $1989,{ }^{20}$ and annual state expenditure per person is currently about $\$ 130$ (£81). ${ }^{21}$ Access to modern medical technology is limited: fewer than 60 percutaneous transluminal coronary angioplasties are performed per million population annually compared with 900 in Western Europe and 1300 in the United States. ${ }^{21}$

Sudden reductions in deaths from ischaemic heart disease that cannot be explained by changes in medical care suggest sudden beneficial effects on later stages of the underlying disease processes. What else could have caused such an effect?

Smoking is an important determinant of circulatory disease. Lung cancer peaked earlier in Poland than in former socialist countries further south, where death certification rates for circulatory disease in men either declined a little (Hungary) or continued to rise (Romania and Bulgaria) (World Health Organisation, unpublished data). However, the sharpness of the change in mortality from ischaemic heart disease and its consistency by age and sex all count against a dominant role for reduced exposure to tobacco.

We found no evidence of a progressive increase in the proportion of people gaining protection against ischaemic heart disease by consuming an average of two or more alcoholic drinks per day. ${ }^{22}$

The recent transition period has probably not led to reduced stress. Despite the rapid recovery of economic output, ${ }^{23}$ unemployment remained at around $15 \%$ of the workforce ${ }^{24}$ in contrast to the preceding era of state assured job security. Between 1989 and 1994 suicide rates increased by about 25\% in men and $10 \%$ in women and homicide increased by over $50 \%{ }^{2526}$

Among documented dietary trends the only plausible candidates we found to explain the fall in deaths from ischaemic heart disease were changes in types of fat consumed and increased supplies of fresh foods.

Consumption of fresh fruit and vegetables has been associated with reduced risk of circulatory disease, ${ }^{27}$ but the association is generally stronger for stroke than for ischaemic heart disease (contrary to the observed change in Poland). Although low consumption of vitamin $\mathrm{C}$ in winter and excess mortality from circulatory causes in winter has a close temporal association, ${ }^{28}$ changes in excess winter mortality were not a distinctive component of the decline in mortality in Poland. Furthermore, since total fruit and vegetable consumption doubled between 1989 and 1992 in the former German Democratic Republic, ${ }^{29}$ any quick acting benefit should have caused a greater decline in mortality from circulatory diseases than was observed (unpublished data). ${ }^{14}$ However, given that the supply of fresh fruit and vegetables in winter and spring constituted perhaps the strongest dietary contrast between eastern and western Europe before 1989, a
- Among former socialist countries Poland has undergone unusually rapid social and economic changes since 1988-9, including aspects of diet

- Mortality from heart disease declined sharply during 1991-4 after long term increases; mortality from stroke declined less strongly

- This study investigated what has changed in Poland to reduce the risks of fatal events in people with established ischaemic heart disease

- Candidate dietary explanations were the substitution of unsaturated for saturated fats and increased consumption of fresh fruit and vegetables

reduction in that difference should remain a candidate to explain any observed convergence in mortality from circulatory causes. ${ }^{30}$

The change in fat consumption has been a consequence of market conditions. General purchasing power fell after 1989, and the withdrawal of large consumer subsidies, especially for foods of animal origin, reduced purchasing power for those foods sharply. ${ }^{31}$ The consequent shifts in demand towards vegetable fats were exploited vigorously-for example, by margarine manufacturers. These margarines were produced with new technology and had low contents of trans fatty acid (K Krygier, personal communication).

Although dietary estimates from food balance sheets are poor measures of absolute consumption, any changes in trend cannot be attributed either to random error or to constant bias. Such changes must reflect either a true change or a new and constantly increasing bias. The latter is an unlikely consequence of administrative disruption, and data collection and processing have not changed in a way that increases bias. Data from the independent household budget survey showed a pattern of change for the major dietary sources of fat consistent with that inferred from the food balance sheets. ${ }^{32}$ This was also shown in the Krakow cohort of the MONICA (monitoring trends and determinants in cardiovascular disease) study (A Gilis-Januszewsk et al, European regional meeting of the International Epidemiological Association, Munster, September 1997). The procedures used for both the food balance sheets and the household budget surveys have remained consistent through the transition period (W Sekula, personal communication).

If a switch from animal to vegetable fats has contributed to the fall in deaths from ischaemic heart disease it does not seem to have acted through reducing cholesterol concentrations. ${ }^{33}$ Such concentrations have not been high in Poland, and neither of the cohorts in the international MONICA programme (Warsaw and Krakow) showed much change in the 10 years to 1993 (A Pajak, personal communication). ${ }^{34}$

Could changes in type of dietary fat produce benefits by other pathways? Two trials in subjects at high risk because of previous heart attacks have shown 
this to be so. ${ }^{356}$ Influences on late stage coronary artery disease-for example, by stabilising plaque-on blood coagulability, and on myocardial susceptibility to arrhythmia induced by hypoxia ${ }^{3738}$ could all contribute to these benefits. Death is more likely to be averted quickly through effects on blood coagulability and on myocardial susceptibility, each of which is quickly affected by dietary change.

There is much still to be explained about why death rates from circulatory diseases vary between populations and over time. After two decades in which mortality rates from circulatory diseases were comparatively stable in women and stable or rising in men in all countries of central and eastern Europe, trends in mortality from these diseases are contrasting in the 1990s. The most recent data show that death rates from ischaemic heart disease in Poland have declined further, albeit less sharply than during 1991-4, and that a decline of almost equal magnitude (though contrasting less with the previous trend) has occurred in the Czech Republic. ${ }^{39}$ Meanwhile, in Hungary, Romania, and Bulgaria there has been little apparent decline. ${ }^{40}$ The scientific opportunities that this heterogeneity of experience presents, particularly to explore effects of dietary changes, should not be missed.

Data were obtained from the Mortality Data Bank of the World Health Organisation, Geneva. We alone accept responsibility for their interpretation. Urszula Wojciechowska helped prepare the data.

Contributors: WAZ initially observed trends in mortality from ischaemic heart disease in Poland. He and AJM assessed various factors that could have contributed to the pattern. WAZ supplied data on mortality and putative causes. JWP prepared the mortality series and the initial draft of the paper. All authors contributed to interpreting the data and to finalising the text. WAZ is guarantor for the study.

Funding: State Committee for Scientific Research and Ministry of Health, Poland.

Conflict of interest: None.

1 Thom TJ, Epstein FH, Feldman JJ, Leaverton PE, Wolz M. Total mortalit and mortality from heart disease, cancer and stroke from 1950 to 1987 in 27 countries: highlights of trends and their interrelationships among causes of death. Bethesda, MD: National Institutes of Health, 1992. (NIH Publication No 92-3088.)

2 World Health Organisation. World health statistics annual. WHO: Geneva 1960-94.

3 Zatonski W. The health of the Polish population. Public Health Reviews (Tel Aviv) 1995;23:139-56.

4 Bobak M, Marmot M. East-West mortality divide and its potential explanations: proposed research agenda. BMJ 1996;312:421-5.

5 WHO MONICA Project. Ecological analysis of the association between mortality and major risk factors of cardiovascular disease. Int J Epidemiol 1994;23:505-16.

6 Schwartz S. The fallacy of the ecological fallacy: the potential misuse of a concept and the consequences. Am J Public Health 1994;84:819-24.

7 Leon DA, Chenet L, Shkolnikov VM, Zakharov S, Shapiro J, Rakhmanova G, et al. Huge variation in Russian mortality rates 1984-94: artefact, alcohol, or what? Lancet 1997;350:383-8.

8 Waterhouse J, Correa P, Muir C, Powell J, eds. Cancer incidence in five continents. Vol 3. Lyons: International Agency for Research on Cancer, 1976:456.

9 Sekula W, Niedzialek Z, Figurska K, Morawska M, Boruc T. Food consumption in Poland converted into energy and nutrients, 1950-1995. Warsaw: Institute of Food and Nutrition, 1996

10 Oles P. The extent of tobacco use in Poland. World Smoking and Health 1983;8:38-42.

11 Central Statistical Office. Roczniki statystyczne [Statistical yearbooks]. Warsaw: CSO, 1970-95.

12 Sieroslawski J. Spoleczno-demograficzne korelaty picia alkoholu w Polsce [Socio.demographic correlates of alcohol drinking in Poland]. Alkoholizm i Narkomania 1995;3:57-77.

13 World Health Organisation. World health statistics annual. Geneva: WHO, 1988: xvii.
14 Okolski M. Migracje zagraniczne w Polsce w latach 1980-1989: Zarys problematyki badawczej [Foreign migrations in Poland 1980-89]. Stud Demogr 1994; 17:3-59.

15 Kozak LJ, Bacon WE, Krzyanowski M, Wojtynjak B. Hospital use in Poland and the United States. Hyattsville, MD, 1988. (Comparative international vital and health statistics reports, series 5, No 2.)

16 Heinemann L, Loewel H, Dahlke D, Eisenblatter D, Greiser E. Validity of the official cardiovascular mortality statistics. Acta Cardiologica 1994;44:338-40.

17 Strom A, Jensen RA. Mortality from circulatory diseases in Norway 194045. Lancet 1951;i:126-9.

18 Strom A. Examination into the diet of Norwegian families during the war-years 1942-45. Acta Med Scand 1948;214(suppl):22.

19 D'Espaignet ET, van Ommeren M, Taylor F, Briscoe N, Pentony P. Trends in Australian mortality 1921-1988. Canberra: Australian Government Publishing Service, 1991:94-5. (Australian Institute of Health mortality series No 1.)

20 Chellaraj G, Adeyi O, Preker AS, Goldstein E. Trends in health status, services, and finance. The transition in central and eastern Europe. Volume 2. Statistical annex. Washington, DC: World Bank, 1996:44. (World Bank technical paper No 348, social challenges of transition series.)

21 Department of Statistical Information and Analysis. Health care in numbers. Warsaw: National Centre for Health System Management, 1995.

22 Doll R, Peto R, Hall E, Wheatley K, Gray R. Mortality in relation to consumption of alcohol: 13 years' observations on male British doctors. BMJ 1994;309:911-9.

23 World Bank. From plan to market: world development report, 1996. Oxford: Oxford University Press, 1996:173.

24 Central Statistical Office. Rocznik statystyczne [Statistical yearbook]. Warsaw: CSO, 1995.

25 Central Statistical Office. Rocznik Statystystyczny demografii [Statistical yearbook of demography]. Warsaw: CSO, 1995.

26 Watson P. Marriage and mortality in Eastern Europe. In: Hertzman C, Kelly S, Bobak M, eds. East-West life-expectancy gap in Europe: environmental and non-environmental determinants. Dordrecht: Kluwer, 1996:152.

27 Ness AR, Powles JW. Fruit and vegetables and cardiovascular disease: review. Int J Epidemiol 1997;26:1-13.

28 Khaw KT, Woodhouse P. Interrelation of vitamin C, infection, haemostatic factors and cardiovascular disease. $B M J$ 1995;310:1559-63.

29 Thiel C, Heinemann L. Nutritional behaviour differences in Germany. Rev Environ Health 1996;11:35-40.

30 Powles JW, Day NE, Sanz MA, Gingham SA. Protective foods in winter and spring: a key to lower vascular mortality? Lancet 1996;348:898-9.

31 Zatonski W. Evolution of health in Poland since 1988. Warsaw: Marie Sklodowska-Curie Cancer Centre, 1996:27.

32 Sekula W. Budzety gospodarstw domowych [Household budget surveys] Warsaw: Central Statistical Office, 1970-94.

33 Law MR, Wald NJ, Thompson SG. By how much and how quickly doe reduction in serum cholesterol concentration lower risk of ischaemic heart disease? BMJ 1994;308:367-72

34 Pajak A. Myocardial infarction-threats and medical care. Longitudinal observational study in 280,000 women and men-POL-MONICA Krakow project. II. Risk factors and mortality due to ischaemic heart disease in men at age 35-64. [In Polish with English abstract.] Przeglad Lekarski (Warsaw) 1996;53:707-12.

35 Burr ML, Gilbert JF, Holliday RM, Elwood PC, Fehily AM, Rogers S, et al. Effects of changes in fat, fish, and fibre intakes on death and myocardial reinfarction: diet and reinfarction trial (DART). Lancet 1989;ii:757-61.

36 De Lorgeril M, Renaud S, Mamelle N, Salen P, Martin JL, Monjaud I,et al. Mediterranean alpha-linolenic acid-rich diet in secondary prevention of coronary heart disease. Lancet 1994;343:1454-9.

37 McLennan P, Howe P, Abeywardena M, Muggli R, Raederstorff D, Mano $\mathrm{M}$, et al. The cardiovascular protective role of docosahexanoic acid. Eur Pharamacol 1996;300:83-9.

38 Charnock JS. Lipids and cardiac arrhythmia. Prog Lipid Res 1994;33: $355-85$.

39 Bruthans J, Bruthansova D, Cervenkova A. Rapid downturn in Czech CVD mortality: the role of social and economic changes [abstract]. Can J Cardiol 1997;13(suppl B):abstract no 0430.

40 World Health Organisation. Health for all data base [computer program]. Copenhagen: WHO Regional Office for Europe, 1997.

(Accepted 22 October 1997)

\section{Endpiece \\ Alternative definitions}

Circumlocution: A literary trick, whereby the writer who has nothing to say breaks it gently to the reader.

Ambrose Bierce, The Cynic's Word Book (1906), subsequently titled The Devil's Dictionary 